\title{
Autophagy in the pancreatic islets after the administration of cladribine in accordance to two different modes of therapy
}

\author{
Ludwik Jasinski, Marta Lis-Sochocka*, Patrycja Chylinska-Wrzos, \\ EWELINA WAWRYK-GAWDA, BARBARA JODLOWSKA-JEDRYCH
}

Chair and Department of Histology and Embryology with Experimental Cytology Unit, Medical University of Lublin, Radziwillowska 11, Poland

\begin{tabular}{l}
\hline ARTICLE INFO \\
\hline Received 26 April 2017 \\
Accepted 20 July 2017
\end{tabular}

Keywords:

pancreas,

autophagy,

cladribine,

LC3B protein

\begin{abstract}
The treatment of neoplastic and neurodegenerative diseases is still difficult. This because the cytostatic drugs have adverse effects on healthy organs. Among the drugs that have been investigated in the therapy of cancers and multiple sclerosis are the purine analogues. The aim of our study was the evaluation of the effect of cladribine on the process of autophagy in the healthy pancreas via two dosage models.

The experiment was conducted on female Wistar rats which were placed within the experimental and control groups of two dosage models: model (A) - cladribine being administered in a daily dose of $0.1 \mathrm{mg} / \mathrm{kg}$ by weight for 7 days, and model (B) - cladribine being administered in a daily dose of $0.07 \mathrm{mg} / \mathrm{kg}$ by weight in 3 cycles of 6 days with 5 weeks break. A-bis and B-bis groups were included within, respectively, groups A and B. Here, decapitation occurred after 4 weeks break in drug administration. In our work, autophagy was investigated via the expression of the LC3B protein (Light Chain 3B protein). The comparison of the results of many independent trials was built upon the use of the Kruskal-Wallis non-parametric test. Significance was set at $\mathrm{p}<0.005$.

In our results, average LC3B expression was observed in $100 \%$ of all cells in the group A, $70 \%$ in group B and $60 \%$ in group B-bis. We not observed average LC3B expression in the other groups. Moreover, a poor reaction was observed in 55\% of all cells in group A-bis. We noted significant relationships between control group and group A, between the control group and group B, and between group A-bis and groups B and B-bis.

These results demonstrate that cladribine has led to the induction of autophagy in the pancreatic islet cells.
\end{abstract}

\section{INTRODUCTION}

Pancreatic cancer is a cancer with high mortality and poor prognosis, the incidence of which increases from year to year. Current treatment is difficult and not very effective, hence, on-going studies take place so as to improve the prognosis. Among the drugs that have been investigated are the purine analogues: fludarabine, which proved to be ineffective [40] and gemcitabine, which has shown some efficacy in studies in vitro and in vivo, alone and in combination with clofarabine [29]. Studies of the use of 5-fluorouracil and gemcitabine carried out by Hashimoto et al. [16], have revealed that in the case of pancreatic cancer, autophagy contributes to tumor cell growth, but also has a cytoprotective function towards the use of 5-fluorouracil or

\footnotetext{
* Corresponding author

e-mail: martasochocka@wp.pl
}

gemcitabine. In their work, the authors evaluated the process of autophagy within the pancreatic cancer cell line PANC-1, via a variety of drug combinations. Herein, Hashimoto et al. [16] took biopsy samples from pancreatic adenocarcinoma in which the anticancer drugs 5-fluorouracil and gemcitabine were administered independently and in combination with the inhibitors of autophagy: chloroquine and wortmannin. However, the role of autophagy in the case of the use of inhibitors of the process still remains unresolved, thus, research is on-going. In contrast, the studies conducted by Yang et al. [39] involving pancreatic cancer cell lines has confirmed the importance of such inhibitors in the process of autophagy. Moreover, the authors suggest that genetic inhibition of autophagy, regardless of the $\mathrm{p} 53$ protein expression, may have clinical utility in the treatment of pancreatic cancer. 
Autophagy, as apoptosis (a type of programmed cell death), is, however, a slower and older phylogenetically process. Autophagy involves the gradual phagocytosis by the cytoplasm of the cell's own building blocks. It is the process responsible for the arrangement of cell components, provides homeostasis in the cytoplasm and the nucleus, and it, thus, prolongs the life of the cell. Autophagy is also an adaptive process, allowing cell survival in extreme conditions, e.g. in the absence of nutrients or in situations of hypoxia $[4,10,25]$. This process can, therefore, be induced in response to environmental cues such as that of changes in nutrient or hormone status, or in response to the effects of pathogens or chemotherapy $[1,11,22]$.

Autophagy begins with an isolation membrane, also known as a phagophore. It is derived from the lipid bilayer of the endoplasmic reticulum, the trans-Golgi and/or endosomes. This phagophore expands to engulf intra-cellular contents, e.g. protein aggregates, organelles and ribosomes, and forms a double-membraned autophagosome. The loaded autophagosome matures through fusion with the lysosome, promoting the degradation of autophagosomal contents by lysosomal acid proteases. There are five key stages in the molecular level: 1) phagophore formation or nucleation; 2) Atg5-Atg12 (Atg - Autophagy protein) conjugation, interaction with Atg16L and multi-merization at the phagophore; 3) LC3 (Light Chain 3) processing and insertion into the extending phagophore membrane; 4) capture of random or selective targets for degradation; and 5) fusion of the autophagosome with the lysosome, followed by proteolytic degradation by lysosomal proteases of engulfed molecules [15].

Conversion of the protein LC3B (Light Chain 3B protein) into a shorter form confirms the formation of autophagosomes [19]. The initial steps of autophagy involve the formation of a double membranous vesicle - a phagophore. As the isolation membrane matures, the scaffolding protein LC3-I and certain lipids are covalently attached to the membrane $[3,15]$. The subsequent conversion LC3-I to LC3-II serves as a marker of heightened autophagic flux [34]. The LC3B protein is the most reliable marker of autophagy.

One of the purine analogs, albeit, the action of which has not been verified in the treatment of pancreatic cancer, is cladribine (2-CdA). This is associated with the toxicity of 2-CdATP in intracellular structures. In proliferating cells, 2-CdA disrupts the balance of deoxynucleotide, inhibiting the activity of ribonucleotide reductase and DNA polymerases, and disrupting the DNA structure by building a diverging chain. Such a state is a signal for termination. However, in cells that are at rest, the accumulation of 2CdATP activates the endonuclease that leads to the formation of cracks in the strand of DNA. This effect initiates repair mechanisms and activates the enzyme politransferasis.

Later recovery processes lead to the depletion of energy NAD stocks, the inhibition of ATP synthesis, further breakdown energy processes and cell death by apoptosis $[6,9$, $20,36,37]$. The mechanism of such effects in the case of 2-CdA is well known, but it seems an interesting issue with regard to autophagy, as is the case of drug combinations of this and gemcitabine or clofarabine. Therefore, our aim was to evaluate the protein LC3B as a marker of autophagy by way of ascertaining the potential positive effects on the regression of autophagy that are change dependent on 2-CdA dose and time of administration or due to 2-CdA supply interruption. Two dosage models were investigated.

\section{MATERIAL AND METHODS}

The experiment was conducted on 30 female Wistar rats, of body weight of approximately $250 \mathrm{~g}$. Throughout the period of the experiment, the animals were housed in identical conditions, and were given standard, granular feed LSM and had access to drinking water. To carry out the experiment, we received consent no 126/2001, issued by the Local Ethical Committee of the Medical University in Lublin.

The rats were randomly allocated to either experimental or control groups. Each of the identified groups was comprised of 5 animals. After the end of the experiment, the animals were decapitated and material for the planned research were taken.

The premise of the experiment included an assessment of the state of the pancreas as brought about via two experimental models. The first model assumed the administration of the 2-CdA in the cycle used to treat hairy cell leukemia in humans. For that group, we extracted an appropriate control group. For a transparent evaluation of the results of the experiment, first model groups were marked with the letter A. The second model consisted of animals which were given 2-CdA according to the schema used in the treatment of multiple sclerosis (MS) in humans. This group also had an appropriate control group. Second model groups were marked with the letter B.

\section{First model - A}

The animals forming the experimental groups A were administered 2-CdA (Biodribin - Institute of Biotechnology and Antibiotics) according to the following schema: Once a day, in the morning, subcutaneously with a needle, in the dose of $0.1 \mathrm{mg} / \mathrm{kg}$ by weight (in a volume of $1 \mathrm{ml}$ ). The 2-CdA was administered for 7 consecutive days, in a fold of the hip, interchangeable left, then right. Through difference in time of decapitation, we were able to generate 2 experimental groups: A and A-bis.

Experimental group A - decapitation occurred and research material collected 24 hours after administration of the last dose of the drug.

Experimental group A-bis - decapitation occurred and research material was collected after a 4 week break in the administration of the drug. During the break, the animals remained on the standard diet with access to drinking water.

Control group KA - the animals remained on the standard diet and received subcutaneous injections of physiological saline in the volume of the administered drug. Decapitation occurred 24 hours after administration of the last injection of saline.

\section{Second model - B}

All the animals in the B experimental groups obtained 2-CdA subcutaneously in a daily dose of: $0.07 \mathrm{mg} / \mathrm{kg}$ by weight (in a volume of $1 \mathrm{ml}$ ) according to the schema used in the treatment of MS in humans - in 3 cycles of 6 days with 5 weeks rest. Injection were made interchangeably 
in either the left or right hip area skin-fold. The B group animals receive unlimited standard diet consisting of LSM feed and drinking water. With regard to time of decapitation, we generated 2 experimental groups: B and B-bis.

Experimental group B - rats were decapitated 24 hours after administration of the last dose of the drug, and research material was collected.

Experimental group B-bis - after administration of the last dose of 2-CdA, the animals were left for a drug-free period of 4 weeks on a standard diet with access to drinking water ad libitum. The animals were then decapitated and research material was collected.

Control group $\mathrm{KB}$ - The animals received subcutaneous injections of physiological saline in the same schema as the drug that was administered in the experimental groups. At 24 hours following administration of the last injection, the animals were decapitated and research material was collected.

After decapitation, the pancreases samples were taken for histological and immunohistochemical (IHC) examination, and were first fixed in Baker's solution, then dehydrated in alcohol with increasing concentration, and subsequently placed in xylene, after which they were rinsed in $10 \%$ buffered formalin. Paraffin blocks were cut on the rotational microtome Leica RM 2135, in $5 \mu \mathrm{m}$ sections which were stained with hematoxylin and eosin $(\mathrm{H}+\mathrm{E})$.

The IHC study of the pancreas was carried out with the use of LC3B antibody markers of autophagy. The IHC reaction has been carried out according to the indirect immunoperoxidase method.

The collected pancreases samples were placed on Polysine slides, then were deparaffined and placed in xylene. Subsequently, they were dehydrated in a series of alcohols with decreasing concentrations, and rinsed with distilled water for 5 minutes. The unveiling of the antigenic sites were made using a thermal method. Herein, samples were incubated in a citrinian buffer solution, and placed within a microwave oven for 3 cycles lasting 5 minutes. After reaching room temperature, the material was rinsed in distilled water. In a later stage, the activity of endogenous peroxidase was blocked by placing the preparations in a mixture of $0.03 \%$ hydrogen peroxide with methanol for the duration of 10 minutes. The samples were then washed in distilled water and TBS (Tris buffered saline) buffer, $\mathrm{pH}$ 7.4. To block places of nonspecific binding, the antigen Normal Diluted Serum approach was employed. The subsequent stage of the procedure involved incubation with primary antibody for a period of 60 minutes, as diluted per the recommendation of the manufacturer: Anti-LC3B antibody, ab48394, ABCAM, at a dilution of $1: 200$.

In a later stage, the specimens were rinsed in TBS buffer. In order to mark reaction sites, we used a diaminobenzidine substrate solution (DAB) to generate a hematoxylin tinge. Samples were then rinsed in running water and distilled in a series of alcohols with increasing concentrations, and, finally, enclosed within a coverslip.

A negative control was undertaken via the elimination of used antibodies.

The material was assessed using the light microscope at magnification $200 \times$ and $400 \times$. The obtained material were analyzed by way of an Olympus BX41 system with digital camera DP 25. All calculations were done via Cell^D.

In the IHC study, we examined the severity of colorful reaction. Under $400 \times$ magnification, 3 fields of vision were selected. These demonstrated the highest volume of color reaction. In this evaluation, we utilized about 50 cells of the endocrine part of the pancreas. Among the cells displaying a positive reaction, we investigated the intensity of protein expression according to the following scale: 0 (0) - no response, $1(+)$ - poor expression, $2(++)-$ the average expression, and $3(+++)-$ a strong expression. We then calculated the percentage of cells showing positive reaction in the different fields of view. Cell calculation was also undertaken to ascertain the appropriate intensity of expression of the proteins.

\section{Statistical methods}

The obtained results were summarized in tables which display the percentages of the severity of the coloured IHC reaction in the various treated groups. The comparison of the results of many independent trials was built upon the use of the Kruskal-Wallis non-parametric test. Significance was set at $\mathrm{p}<0.005[24,33]$. The analysis was performed via the Statistica program 10.

\section{RESULTS}

\section{H+E staining}

We observed degeneration of the cytoplasm and pyknosis of nuclei in the group A in the group A-bis, that we described previously [18].

In group B, the endocrine cells had very clear nuclei outlines that were characteristically pyknotic. The cytoplasm of these cells also showed an affinity to basophile dyes. In addition, the characteristics of vacuolar degeneration were only noticeable in the individual cells of the islands alone (Fig. 1a). In group B-bis, the cells had nuclei with globular characteristics. These displayed a very strong chromatin framework. Moreover, some of these demonstrated the characteristics of pyknosis. Finally, most of the cells showed cytoplasm that was stained pink, while the remainder had cytoplasm that was stained a delicate blue colour (Fig. 1b).

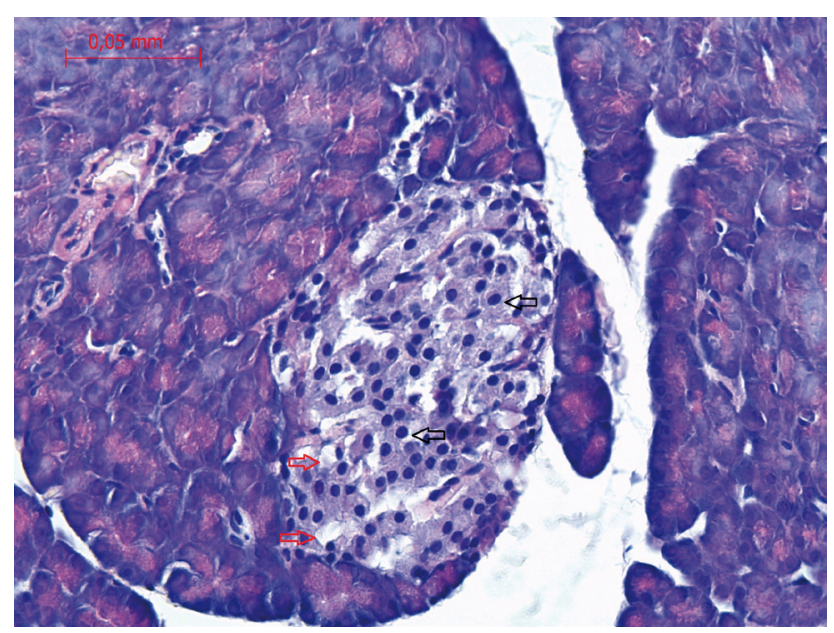

Figure 1a. Experimental group B. Pyknosis in a majority of cell nuclei (black arrows). Vacuolar degeneration (red arrows) was noticeable in the individual cells. H\&E staining 


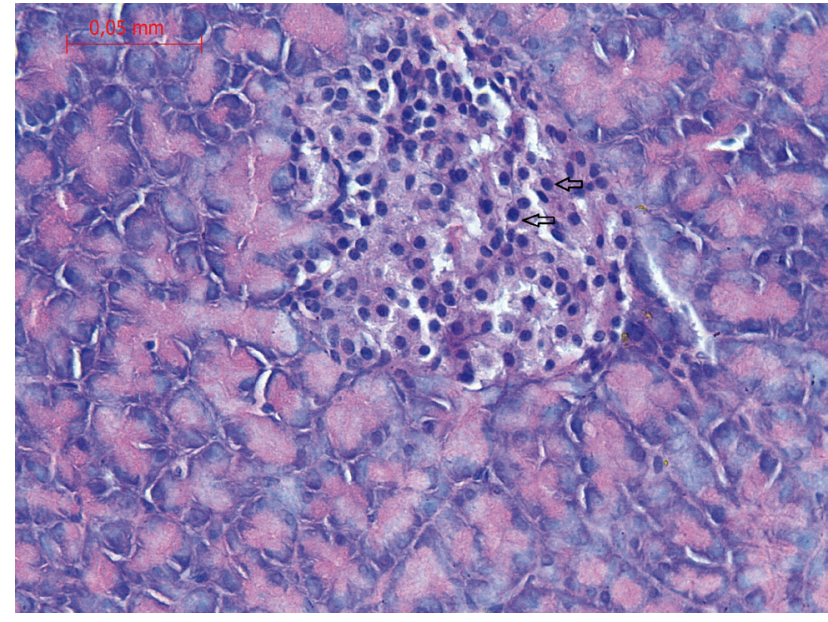

Figure 1b. Experimental group B-bis. Pyknosis in the nuclei of some cells (black arrows). H\&E staining

\section{Expression of LC3B protein}

In all of the studied groups, there were no cells with a strong expression $(+++)$ of the assessed protein. In the KA group, poor positive cytoplasmic reaction was observed in $78,13 \%$ of all the studied pancreatic endocrine cells. Moreover, in parts of these cells (especially those located peripherally), a lack of response was particularly noticeable (Fig. 2a and 3). In group KB, about $43 \%$ of all analyzed cells also showed poor cytoplasmic reaction (Fig. 2b and 3).

In group A, all cells (100\%) demonstrated an average IHC reaction expression. Brown coloured immunoprecipitations were also seen in the cytoplasm and the nuclei of the analyzed cells (Fig. 2c and 3). In the group A-bis, about $55 \%$ of all analyzed cells had poor cytoplasmic reaction (Fig. 2d and 3).

In groups B and B-bis (Fig. 2e and 2f), an average LC3B protein expression was evident in the cytoplasm of the endocrine cells. In group B, the calculated figure was about 70\% of all cells (Fig. 3), while in group B-bis, this figure was about $60 \%$ of all cells (Fig. 3 ).

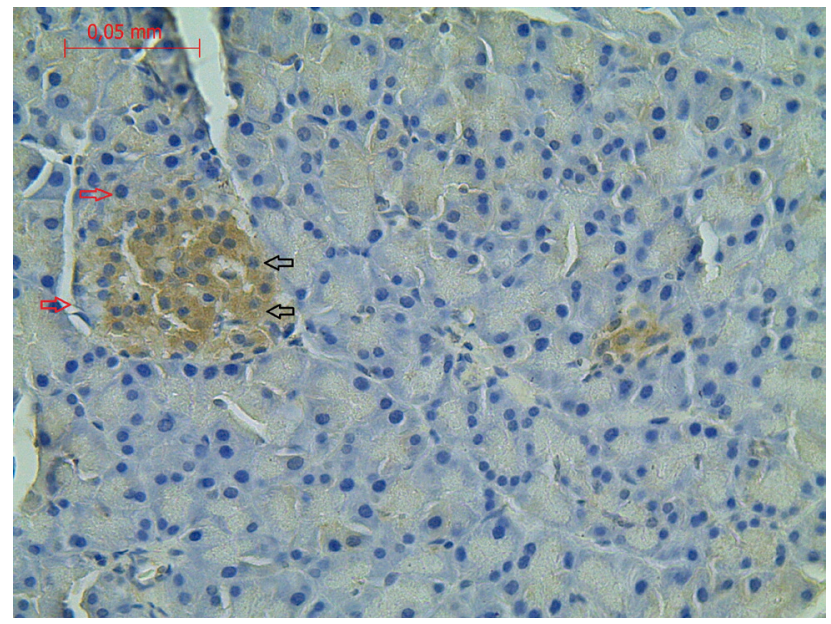

Figure 2a. Control group KA. LC3B protein expression. Most cells evidenced poor positive cytoplasmic reaction (black arrows). Some peripheral cells demonstrated a lack of response (red arrows)

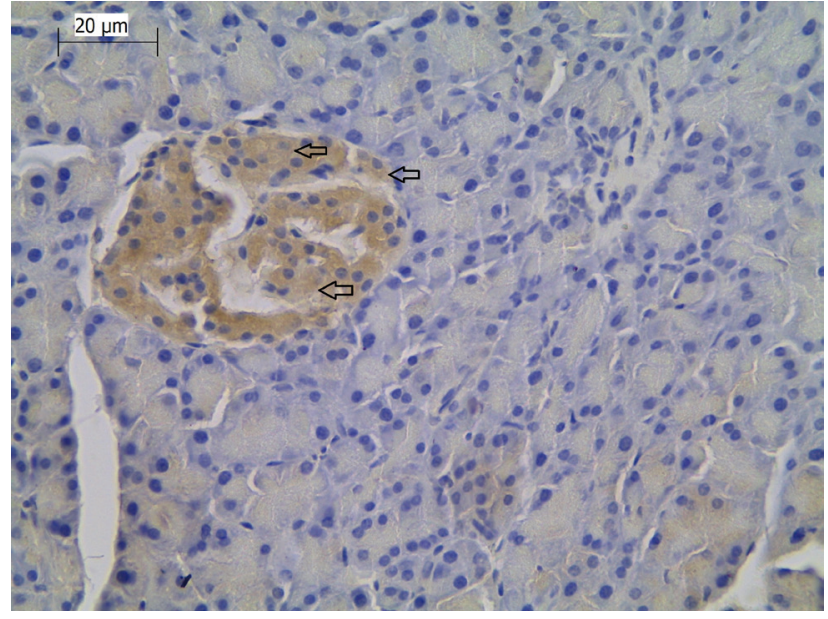

Figure $2 \boldsymbol{b}$. Control group KB. LC3B protein expression. All cells showed poor cytoplasmic reaction (black arrows)

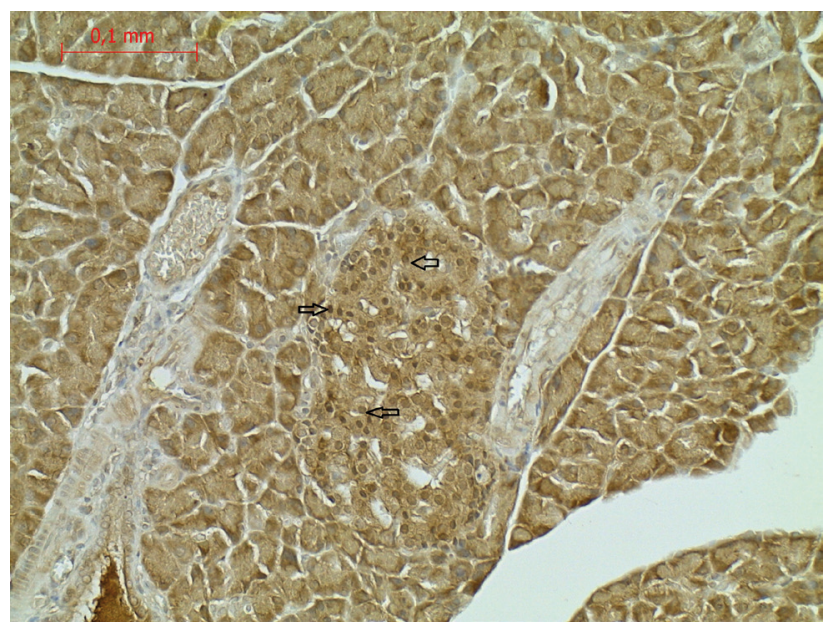

Figure 2c. Experimental group A. LC3B protein expression. All cells demonstrated average expression. Brown coloured immunoprecipitations were seen in the cytoplasm cells (black arrows)

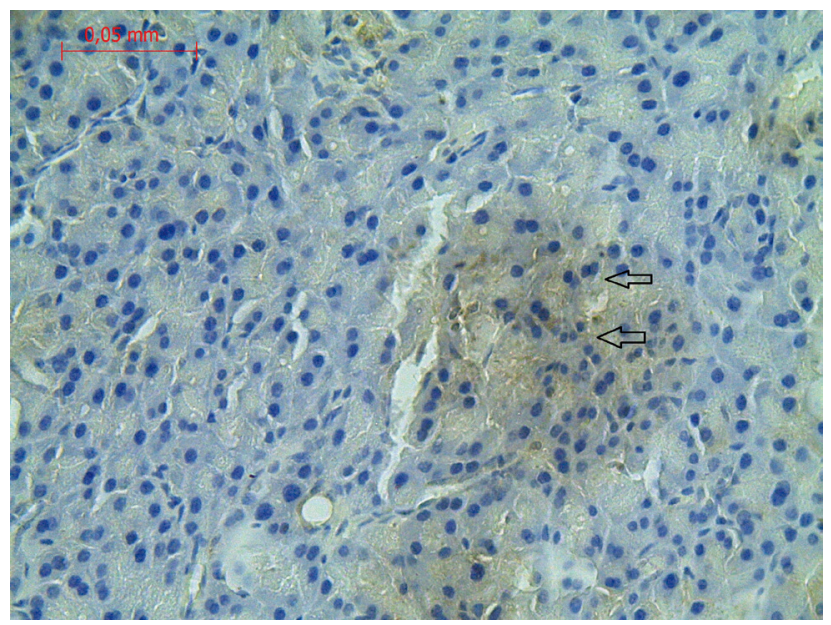

Figure $2 \boldsymbol{d}$. Experimental group A-bis. LC3B protein expression. Many cells showed poor cytoplasmic reaction (black arrows) 


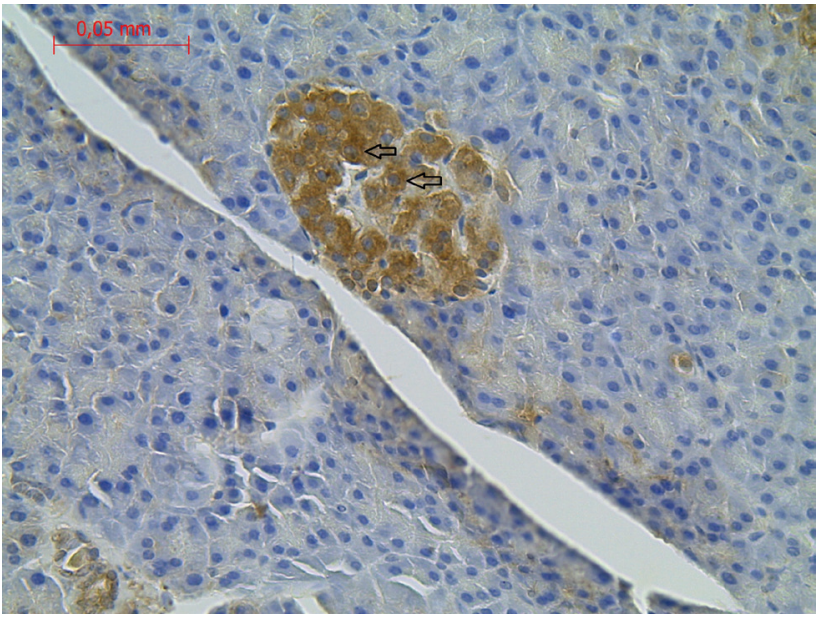

Figure 2e. Experimental group B. LC3B protein expression. An average expression of protein content was visible in the endocrine cell cytoplasm (black arrows)

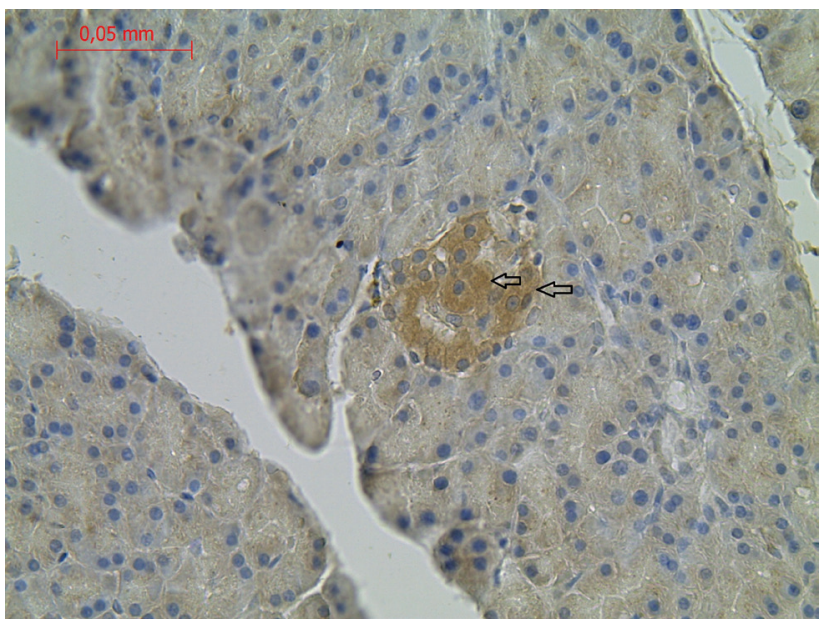

Figure 2f. Experimental group B-bis. Expression of LC3B protein. An average reaction was seen in the cell cytoplasm (black arrows)

The carrying out of a comparative analysis of statistical significance between groups allowed us to determine that a significant relationship exists between both control groups and group A, while there was no such dependence seen with regard to group A-bis. A significant relationship was also found between both control groups and group B. Furthermore, there were no statistical significance between groups $\mathrm{A}$ and $\mathrm{B}$, and $\mathrm{A}$ and $\mathrm{B}-\mathrm{bis}$, while there was a significant relationship between group A-bis and groups B and B-bis (Table 1).

Table 1. p-value for multiple comparisons

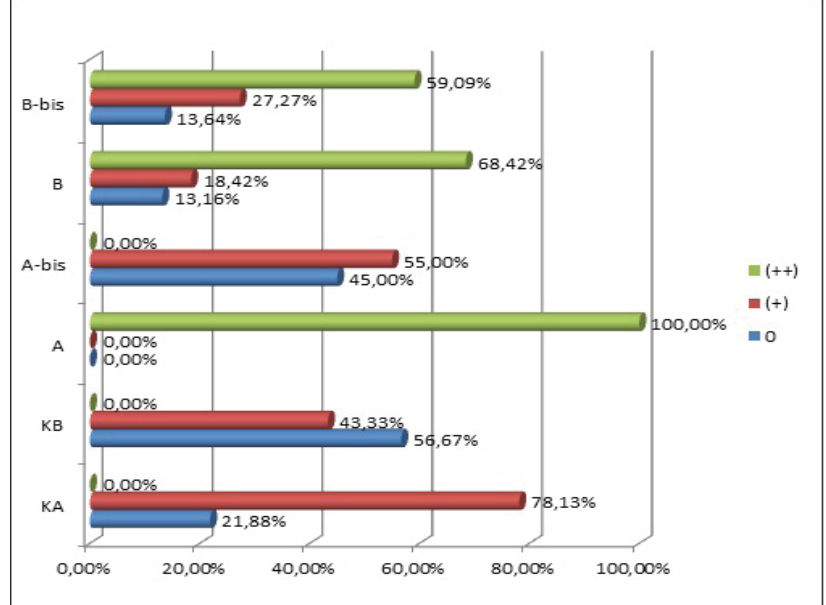

Figure 3. LC3B protein expression. In group A, all cells (100\%) demonstrated an average $(++)$ expression; in group A-bis, about $55 \%$ of all analyzed cells showed poor $(+)$ cytoplasmic reaction. In group B, $70 \%$ of all cells revealed an average response $(++)$; in group B-bis, about $60 \%$ of all cells showed an average response $(++)$. In group KA, about $80 \%$ of all cells showed a poor $(+)$ expression of the analyzed protein; in group $\mathrm{KB}$, about $44 \%$ of all cells showed a similar reaction $(+)$

\section{DISCUSSION}

In the healthy functioning body, all kinds of physiological eliminations of cells ensure the existence of the optimum number needed for the proper functioning of the body as a whole. Any disorders resulting from the errors that come about during the replication or through disorders of the cell cycle can lead to proliferation, and can, consequently, be the cause of certain diseases such as the various cancers. Indeed, uncontrolled cell division, prevented proliferation, impaired apoptosis, autophagy, or necrosis, as well as disturbed differentiation, are the basis for the occurrence of many cancers (e.g.: the leukemias, lymphomas and sarcomas), as well as several neurodegenerative diseases and autoimmune disorders (MS, Alzheimer's disease, Parkinson's disease, systemic lupus erythematosus, and thyroiditis-Hashimoto) $[1,2,7,12,31]$.

The possibility of interfering in the course of the key cell life processes enables a better chance of slowing or halting the progress of the aforementioned diseases. In the available literature, there are few reports devoted to the action of chemotherapeutic agents with regard to effects on healthy cells. However, it is now known that conventional chemotherapy agents can induce apoptosis. Furthermore, other forms of cell depletion, i.e. the so-called 'no apoptoptic death',

\begin{tabular}{|c|c|c|c|c|c|c|}
\hline \multirow{2}{*}{ Groups } & \multicolumn{6}{|c|}{$\begin{array}{l}\text { Kruskal-Wallis non-parametric test: } \mathrm{H}(6, \mathrm{~N}=212)=130.9768 \\
\mathrm{p}=\mathrm{ddd} 0.000\end{array}$} \\
\hline & $\begin{array}{c}\text { KA } \\
\text { R: } 79.781 \\
\end{array}$ & $\begin{array}{c}\mathrm{KB} \\
\mathrm{R}: 57.167\end{array}$ & $\begin{array}{c}\mathrm{A} \\
\mathrm{R}: 171.50\end{array}$ & $\begin{array}{c}\text { BA-bis } \\
\text { R: } 64.750\end{array}$ & $\begin{array}{c}\mathrm{B} \\
\mathrm{R}: 138.47\end{array}$ & $\begin{array}{c}\text { B-bis } \\
\text { R: } 130.93\end{array}$ \\
\hline $\mathrm{KA}$ & & 1.000000 & $0.000000 *$ & 1.000000 & $0.001400 *$ & 0.054729 \\
\hline KB & 1.000000 & & $0.000000 *$ & 1.000000 & $0.000001 *$ & $0.000385 *$ \\
\hline A & $0.000000 *$ & $0.000000 *$ & & $0.000000 *$ & 0.327626 & 0.244393 \\
\hline A-bis & 1.000000 & 1.000000 & $0.000000 *$ & & $0.000285 *$ & $0.010068 *$ \\
\hline B & $0.001400 *$ & $0.000001 *$ & 0.327626 & $0.000285 *$ & & 1.000000 \\
\hline B-bis & 0.054729 & $0.000385 *$ & 0.244393 & $0.010068 *$ & 1.000000 & \\
\hline
\end{tabular}


as well as autophagy, necrosis and mitotic catastrophe, can stimulate the effect of aging [25].

In the works of Jędrych et al. [18] and that of WawrykGawda et al. [37], the authors demonstrate that the administration of 2-CdA in rats in accordance with the scheme used to treat hairy cell leukemia, blocks the proliferation of epithelial ovarian cells in rats, and induces apoptosis in such cells $[18,37]$. What is more, in another study, Wawryk-Gawda et al. [36] demonstrate that 2-CdA administered according to this scheme initiates the apoptotic pathway in the epithelial ovarian cells of rats. Herein, the 4-week break in the therapy did not significantly instigate an improvement in the morphology of these cells. Similar results are also seen in the study by Chylińska-Wrzos et al. [9]. In this, 2-CdA administered according to the scheme of MS, induces the internal apoptotic pathway in the epithelial cells of rats. Furthermore, in another work [8], the author reveals that the 4-week break in the administration of the drug has some effect on the regeneration of tissue.

Such reports, devoted to the phenomenon of autophagy, show that this is a process that regulates cell degradation and the recycling of cellular components. Such effects play important roles in inflammation and in the progress of cancer of the pancreas. It also must be noted that the results of the work of Rivera et al. [26], suggest that the process of lysosomal autophagy protects pancreatic beta cells from the toxic effects of islet amyloid polypeptides in the case of type II diabetes. Moreover, studies conducted by Yang et al. [38], on cancer cell lines, have confirmed the important role of autophagy in the progress of pancreatic cancer. Of note, in the conclusions of their paper, the authors suggest that the genetic inhibition of autophagy, regardless of the p53 protein expression, may have clinical utility in the treatment of pancreatic cancer. Thus, autophagy is a topical subject $[13,28]$. Indeed, in current literature, there are controversial reports about the role of autophagy in the cancer of the pancreas. Herein, some researchers have demonstrated that this process has a cytoprotective function on cells of the pancreas in the case of pancreatic cancer [14,16,39].

According to the research conducted by Ropolo et al. [27], chemotherapy by way of administering an analogue of deoxycytidine-gemcitabine (pyrimidine antimetabolite), which is the current standard in the treatment of pancreatic cancer, induces autophagy in pancreatic cancer cells. The early induction of autophagy by gemcitabine leads to the death of cancer cells, and this process is mediated by the activation of the transmembrane protein, VMP1, that triggers autophagy in mammals. Additionally, inhibition of autophagy by way of the adminstration of 3-methyladenine, a widely used autophagy inhibitor, significantly reduces the percentage of cell death in response to gemcitabine. The fact that inhibition of the process of autophagy reduces the percentage of pancreatic cancer cell with features of death, supports the hypothesis that the process of autophagy enhances the antitumor potency of chemotherapeutic drugs.

Other investigators have reported that autophagy improves the survival of cancer cells by generating the resistance of these cells to the cytostatic drugs $[21,23]$. In their work, these authors show that the process of autophagy in cancer cells of the pancreas is very complicated, and there are different molecular mechanisms involved. The unraveling of this complexity still continues.

In our work, we had taken on the study of the effect of the effects of 2-CdA administration upon cells of the endocrine part of the heathy pancreas, doing so by way of analyzing this effect on the morphology of the pancreas. The study, thus, was intended to determine the immunohistochemical expression of the protein LC3B for autophagy. Our work was conducted by way of two approach models: Model A - the so-called "leukemoid" - wherein 2-CdA was administered in accordance to the administration model of leukemia treatment; and model B - in which 2-CdA was administered according to the model used in the treatment of MS. For both, A and B - bis groups were formed. In these, material was collected 4 weeks post-treatment.

The examination of microscopic preparations of the pancreas stained with $\mathrm{H}+\mathrm{E}$ has revealed that following the administration of 2-CdA, the architectural construction of the pancreas does not deviate from the norm. Still, in some islet cells, particularly in group A and A-bis, vacuolar degeneration of the cytoplasm was observed, that we described previously [17].

The presence of vacuolar degeneration is an expression of the undergoing of adaptive changes in the cell. These come about by the action of damaging factors and by hypoxia. Hypoxia interferes with the activity of ATPase, thereby lowering the sodium concentration in the cytosol. As sodium and chlorides are responsible for binding water, this leads to the accumulation of water in the cytoplasm, in the mitochondria and in the endoplasmic reticulum (which is the site of most detoxification processes in the cell). This water accumulation is a reversible process that comes about when the effect of the damaging factor ceases, and ATP production returns to normal [32].

A pyknotic nucleus is characterized by a high density of nuclear chromatin. This effect is indicative of degenerative changes occurring within the cell, and it comes about because of the initial changes in cell death - when the cell is in a state of apoptosis and necrosis [5]. Therefore, it can be presumed that 2-CdA as given in the leukemic model has resulted in damage of the pancreatic islet cells, and a 4-week withdrawal did not induce major changes. It should be underlined that significantly less degeneration of cells was seen that held the characteristics of vacuolar degeneration, but we also saw cells with pyknotic nuclei within the pancreatic islets.

The samples of the pancreas obtained from animals treated with 2-CdA for a longer period as per the treatment regime for MS, showed similarity to that of the previous group. In the islands, we saw pancreatic cells with pyknotic nuclei, yet, fewer cells showed signs of vacuolar degeneration. Moreover, after a 4 week break in administration, while the image did not fundamentally changed, there was no cells with the characteristic signs of degeneration. This picture may suggest that the changes which had occurred may be due to the action of 2-CdA on the cells of the endocrine pancreas.

In our study, LC3B protein expression was observed on the pancreatic sections taken from the animals of all groups. This indicates the occurrence of autophagy. Of note, the 
IHC reaction varied in severity. In group A, $100 \%$ of all cells showed the expression of the protein LC3B, while in the A-bis group we observed just poor expression of LC3B. Therefore, it can be assumed that the 7 days administration of 2-CdA stimulated the process of autophagy, while after a 4 week break in the administration of the drug, the process of autophagy was inhibited. As is known, autophagy plays an important role in cell physiology. It is a catabolic process that involves the turnover and elimination of proteins and defective or old cell organelles [30]. Hence, it is appropriate to conclude that a period of four weeks break in administration of 2-CdA may have brought about enough time to regain the right quality with regard to basic cellular components.

In group B and B-bis, the percentage of pancreatic islet cells in which the process of autophagy was observed (positive expression of LC3B) was similar, and it amounted to about $86 \%$ of the whole. In this model, even a four week break in the delivery of 2-CdA did not change the intensity of the autophagy process.

\section{CONCLUSIONS}

The results of our study indicate that cladribine administered as a lower dose for a longer time induces minor degenerative changes, while its administration in higher doses, for a short time cycle induces greater degenerative changes. Moreover, the process of autophagy increases in the pancreatic islet cells after cladribine administration, and remains at a high level in the regenerated tissues.

\section{CONFLICT OF INTEREST}

The authors of this manuscript have no conflict of interest to declare.

\section{ACKNOWLEDGMENT}

This work was supported by research from the Medical University in Lublin, Poland (No. MNmb245).

\section{REFERENCES}

1. Aghajan M., Li N., Karin M.: Obesity, autophagy and the pathogenesis of liver and pancreatic cancers. J Gastroenterol Hepatol., 27, 10, 2012. doi: 10.1111/j.1440-1746.2011.07008.x.

2. Agostini S. et al.: A new dual-promotor system for cardiomyocyte - specific conditional induction of apoptosis. Biomed Res Int., 13, 2013, doi:10.1155/2013/845816.

3. Barth S., Glick D., Macleod K.F.: Autophagy: assays and artifacts. J. Pathol., 221, 117, 2010.

4. Bergamini E. et al.: The anti-aging effects of caloric restriction may involve stimulation of macroautophagy and lysosomal degradation, and can be intensified pharmacologically. Biomed Pharmacother., 57, 203, 2003

5. Burgoyne L.A.: The Mechanisms of Pyknosis: Hypercondensation and Death. Experimental Cell Research, 248, 214, 1999.

6. Cardoen S. et al.: Effects of 2-Chloro-2'-Deoxyadenosine on the Cell Cycle in the Human Leukemia EHEB Cell Line. Nucleosides, Nucleotides \& Nucleic Acids, 23, 1425, 2004.

7. Chilmonczyk Z.: Receptory śmierci - cel molekularny leków przeciwnowotworowych. Gazeta Farmaceutyczna, 1, 34, 2009.

8. Chylińska-Wrzos P. et al.: Expression of p53 protein and the histomorphological view of epidermis in experimental animals after cladribine application. IJVR, 15, 198, 2014.
9. Chylińska-Wrzos P. et al.: The intrinsic or the extrinsic pathways of apoptosis in the epidermis after cladribine application? Journal of Biomedical Science and Engineering, 6/3, 265, 2013.

10. Deretic V.: Autophagy in innate and adaptive immunity. Trends Immunol., 2, 523, 2005.

11. Deretic V., Saitoh T., Akira S.: Autophagy in infection, inflammation and immunity. Nat Rev Immunol., 13, 10, 722, 2013.

12. Fischer U., Schulze-Osthoff K.: New approaches and therapeutics targeting apoptosis in disease. Pharmacol Rev., 57, 187, 2005.

13. Fortunato F. et al.: Impaired Autolysosome Formation Correlates With Lamp-2 Depletion: Role of Apoptosis, Autophagy, and Necrosis in Pancreatitis. Gastroenterology, 137, 350, 2009.

14. Fujii S. et al.: Autophagy is activated in pancreatic cancer cells and correlates with poor patient outcome. Cancer Sci., 99, 1813, 2008.

15. Glick D., Barth S., Macleod K.F.: Autophagy: cellular and molecular mechanisms. J. Pathol., 221, 3, 2010.

16. Hashimoto D. et al.: Autophagy is needed for the growth of pancreatic adenocarcinoma and has a cytoprotective effect against anticancer drugs. Eur J Cancer, 50, 1382, 2014.

17. Jasinski L. et al.: A comparison of caspase 3 expression in the endocrine and exocrine parts of the pancreas after cladribine application according to the "leukemic" schema. Curr Issues Pharm Med Sci., 30, 9, 2017.

18. Jędrych M. et al.: Immunohistochemical evaluation of cell proliferation and apoptosis markers in ovarian surface epithelial cells of cladribine-treated rats. Protoplasma, 250, 1025, 2013.

19. Klionsky D.J. et al.: Guidelines for the use and interpretation of assays for monitoring autophagy in higher eukaryo. Autophagy, 4, $151,2008$.

20. Leist T.P., Weissert R.: Cladribine: Mode of Action and Implications for Treatment of Multiple Sclerosis. Clin Neuropharm., 34, 28, 2011.

21. Mukubou H. et al.: The role of autophagy in the treatment of pancreatic cancer with gemcitabine and ionizing radiation. Int $J$ Oncol., 37, 821, 2010.

22. Ozaki N. et al.: Autophagy regulation in pancreatic acinar cells is independent of epidermal growth factor receptor signaling. Biochem Biophys Res Commun., 446, 224, 2014.

23. Pardo R. et al.: Gemcitabine induces the VMP-1 mediated autophagy pathway to promote apoptotic death in human pancreatic cancer cells. Pancreatology, 10, 19, 2010.

24. Petrie A., Sabin C. editors (2006). Statystyka medyczna w zarysie. Warszawa, PZWL.

25. Ricci M., Zong W.: Chemotherapeutic approaches for targeting cell death pathways. Oncologist, 11, 342, 2006.

26. Rivera J. et al.: Autophagy defends pancreatic beta cells from human islet amyloid polypepetide - induced toxity. J. Clin Invest., 124, 8, 3489-500, 1981, doi: 10.1172/JCI71981.

27. Ropolo A. et al.: Chemotherapy and autophagy-mediated cell death in pancreatic cancer cells. Pancreatology, 12, 1, 2012.

28. Rosenfeldt M. et al.: p53 status determines the role of autophagy in pancreatic tumour development. Nature, 12, 504, 296, 2013.

29. Sau W.H., Mody H.R., Rajgopal G.: Overcoming nucleoside analog chemoresistance of pancreatic cancer: A therapeutic challenge. Cancer Letters, 320, 138, 2012.

30. Shuang W. et al.: Pancreatic islet cell autophagy during aging in rats. Clin Invest Med., 36, 2, E72-E80, 2013.

31. Smolewski P., Darzynkiewicz Z.: Współczesne metody badania apoptozy. Acta Haematologica Polonica, 34, 35, 2003.

32. Stachura J. (2003). Uszkodzenie i śmierć komórki. In: Patologia znaczy słowo o chorobie, vol I - patologia ogólna. Stachura J., Domagała W. (editors). PAU, Kraków, PUK; p. 12-13.

33. Stanisz A. editor (2005). Biostatystyka. Podręcznik dla studentów i lekarzy. Kraków, WUJ.

34. Vernon P.J., Tang D.: Eat-me: autophagy, phagocytosis, and reactive oxygen species signaling. Antioxid. Redox Signaling, 18, 677, 2013.

35. Wawryk-Gawda E. et al.: Use of selected purine analogs in neoplastic and autoimmune diseases. Annales Universitatis Mariae CurieSkłodowska, Sectio DDD: Pharmacia, 24/4, 29, 2011.

36. Wawryk-Gawda E. et al.: Intrinsic apoptosis pathway in fallopian tube epithelial cells induced by cladribine. Scientific World Journal, 2, 928036, 2014, doi: 10.1155/2014/928036. 
37. Wawryk-Gawda E. et al.: $\mathrm{P} 53$ protein in proliferation, repair and apoptosis of cells. Protoplasma, 251, 525, 2014.

38. Yang A. et al.: Autophagy is critical for pancreatic tumor growth and progression in tumors with p53 alterations. Cancer Discov., 4 , 905, 2014.

39. Yang S. et al.: Pancreatic cancers require autophagy for tumor growth. Genes Dev., 25, 717, 2011.

40. Zulian G.B. (1994). A review of fludarabine and cladribine in solid tumors. In: Innovate Antimetabolites' in Solid Tumors. Aapro M.S. (editor). Berlin, Springer Verlag; p. 29-3. 